\title{
Developing Primary Liaison Psychiatric Services for HIV/AIDS Patients in Community
}

\author{
Ahsan Ahsan, Retno Lestari \\ Department of Nursing, University of Brawijaya, Indonesia
}

\begin{tabular}{l} 
Article Info \\
\hline Article history: \\
Received Jun 10, 2017 \\
Revised Aug 12, 2017 \\
Accepted Aug 27, 2017 \\
\hline
\end{tabular}

\section{Keyword:}

Community

HIV/AIDS

Liaison

Psychiatric services

\begin{abstract}
In Indonesia, the number of HIV/AIDS patients has grown at significant level. HIV can be a source of major stress which can lead to changes in mental health, such as persistent sadness, feeling empty and anxiety. The ability of liaison officer could help patients reduce their psychiatric problems and at the same time it can greatly affect patients' risks for transmission of HIV to others. This study aimed to analyze the effect of developing primary liaison psychiatric services for HIV/AIDS patients on the abilities of health care workers to provide treatments. This study used a quasi experimental design with one group pretest-posttest which included 64 health care workers aged between 20 and 50 years from the Community-Integrated Health Care in East Java. The inclusion criteria were nurses and physician in CommunityIntegrated Health Care. The respondents were assessed using the Abilities of Health Care Workers Checklist pre-treatment and post-treatment. The outcomes were analyzed using the Wilcoxon signed rank test. There was a significant increased in the abilities of health care workers to provide psychiatric services after treatment $(\mathrm{p}<0.05)$. The liaison psychiatric services were considered to be effective in increasing the abilities of health care workers in improving the treatment of HIV/AIDS.
\end{abstract}

Copyright () 2017 Institute of Advanced Engineering and Science. All rights reserved.

\section{Corresponding Author:}

Ahsan,

Department of Nursing,

University of Brawijaya,

Jl. Veteran-Malang, Jawa Timur, Indonesia, 65145.

Email: ahsan@yahoo.co.id

\section{INTRODUCTION}

In Indonesia, the number of Human Immunodeficiency Virus (HIV)/Acquired Immune Deficiency Syndrome (AIDS) patients has grown at significant level. It is estimated that around 690,000 patients living with HIV/AIDS. Low treatment, lack of accurate health knowledge about HIV/AIDS and the attitude of society to understand their problems are the main reasons for the spread of HIV in Indonesia [1].

HIV can be a source of major stress which can lead to changes in mental health. Emotional problems are the most common mental disorders among HIV patients, such as depression, persistent sadness, feeling empty and anxiety. The prevalence of depression are doubled among HIV patients than other sexually trasmitther disease. Previous studies also explored that HIV affects cognitive functions and other mental disorders such as psychosis. They show more feelings of anger, guilt and have more suicidal thoughts [2],[3].

There have been explanations about the link between HIV and mental illness. Common factors which can be found are social predisposition factors such as social stigma, homelessness, poverty and substance misuse [4]. Social stigma is still the main reason why HIV patients are afraid to see health professionals to seek treatment. Studies showed that HIV/AIDS still thrive in our cultures because people fail to get help [5]. 
The ability of liaison officer in primary care could help patients reduce their psychiatric problems and at the same time can greatly affect patients' risks for transmission of HIV to others. In general, patients consult to health care workers in primary care planned to explain their feelings. However, commonly health care workers focus primarily on the physical symptoms and patients may express their distress indirectly. It happened as patients have difficulties to express directly. Therefore, building a good relationship between health professionals and patients is very important [6].

Liaison psychiatry services in primary care bridge the gap between mental and physical health. It was developed to provide a range of patient care, such as assessments, evaluation, outpatient consultations etc. The benefit of developing liaison psychiatric services is a collaborative effort between health professionals, patients and all system to work together to support mental health condition among HIV/AIDS patients [7].

Collaborative program facilitates mental health intervention to patients by managing HIV cases in collaboration with health professionals (physicians and nurses), and proved to be effective for the management of mental health issues in primary care [8]. In addition, primary liaison psychiatric services reduced mental illness up to 3 months, as well as increasing satisfaction and adherence to medication up to 12 months, particularly among depressed patients [9].

Therefore, this study aimed to analyze the effect of developing primary liaison psychiatric services for HIV/AIDS patients on the abilities of health care workers to provide treatments, both physical and mental health condition.

\section{RESEARCH METHOD}

The conceptual framework of this study explained in details in Figure 1. Liaison psychiatric services which based in primary care provided consultation, education, supervision, support and research. During consultation session, health care workers delivered mental health intervention as well as physical health [9]. Liaison services used a collaborative care, whereby all health professionals work together with nurses and doctors to discussed HIV cases.

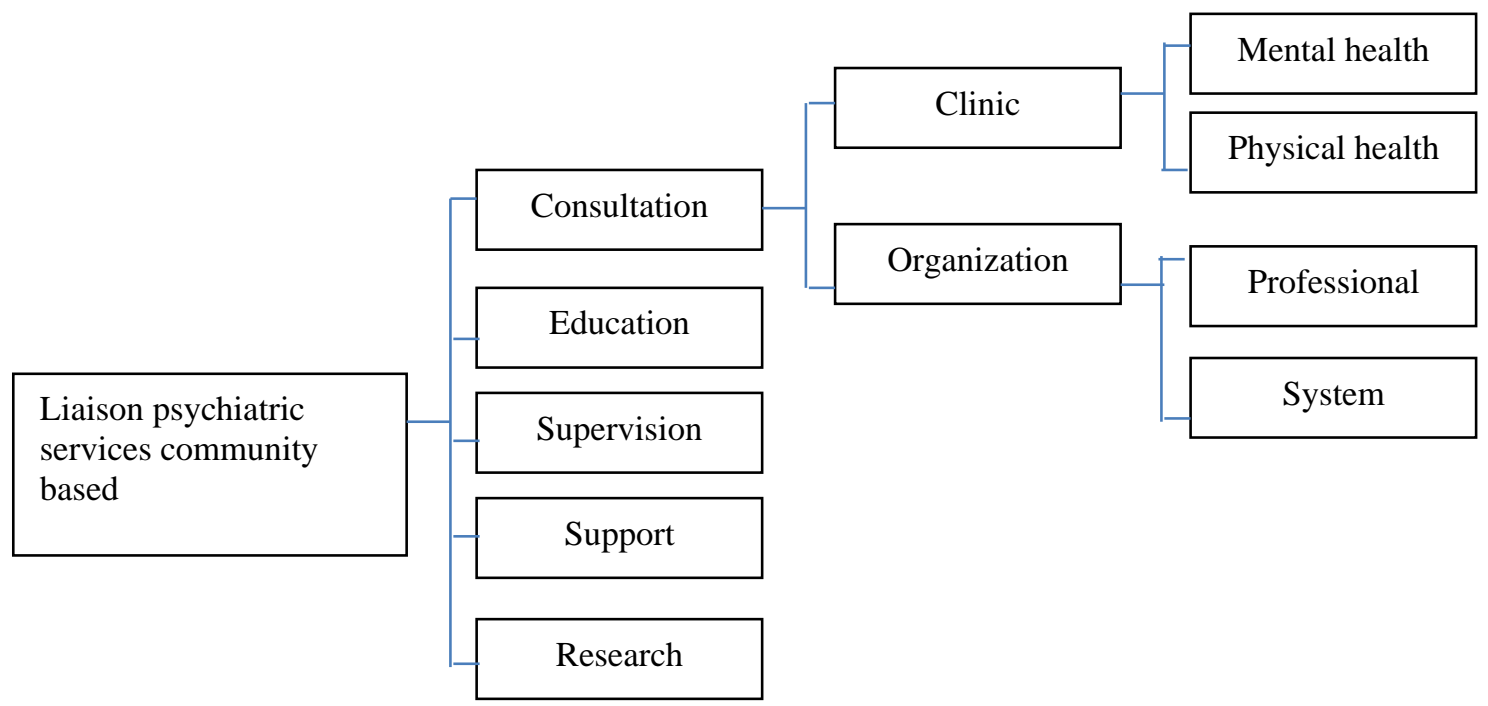

Figure 1. The conceptual framework of liaison psychiatric services in primary care

This pilot study used a quasi experimental design with one group pretest-posttest to analyze the effect of developing primary liaison psychiatric services for HIV/AIDS patients on the abilities of health care workers to provide treatments among 64 health care workers in a Community-Integrated Health Care in East Java. To minimize the confounding factors, the researchers restricted respondents into several inclusion criteria: [1] nurses and physician in Community-Integrated Health Care, [2] have never had the program of liaison psychiatric services, [3] willing and able to participate in all sessions and [4] minimum of 3 years experience of handling HIV patients.

Purposive sampling used for recruiting respondents which consists of 6 physicians and 58 nurses from three community-integrated health center (Puskesmas) in East Java. The researchers asked health 
professionals whether they agreed to participate in the study. Consent was signed by health professionals after each respondents had explanations about the study purpose.

Consent was signed after each participant had explanations about the study purpose. Ethical approval was gained from the Health Research Ethics Community, Faculty of Public Health Airlangga University, April 2016 (No: 153-KPK). Written approval from the site was also obtained. The respondents were assessed using instrument the Abilities of Health Care Workers Checklist pre-treatment and posttreatment. Scale used in the research was the confidence scale that the reliability coefficient alpha $(\alpha)=0.9$ so it can be said that the item is quite valid and reliable.

Data were collected between November 2016-March, 2017. This program was held in communityintegrated health center (Puskesmas) which was located in East Java. There were four sessions of training which was scheduled twice in a month, as explained below:

a. First session: Assessing mental health problems among HIV patients. In this session, the respondents were trained to identify both physical and mental health issues that commonly happened as consequences of diagnosed with HIV. Also, they had opportunities to express any difficulties related to mental health assessment.

b. Second session: Caring for HIV patients. In this session, respondents were trained to care for HIV patients, which includes physical and mental health care

c. Third session: Providing several relaxation therapies during consultation. In this session, there were several psychosocial interventions to reduce mental health issues in HIV patients.

d. Fourth session: Patient and families management. In this session, respondents practiced to explore the burden of treatment in HIV patients.

During the program of liaison psychiatric services, both physician and nurses worked together to collaborate in the treatment. All health care workers have experienced in handling HIV patients before and knew about the characteristics patients. Therefore, matching this process could increase the program outcomes. Collaborative screening in a team can further increase the outcomes of HIV intervention. Collaborative working requires health professionals to support improvements in both the mental and physical health of the people they work with [10]. To enhance the delivery of health care, a multidisciplinary community team has to develop the program of liaison psychiatric services in primary care.

In data analysis, mean and standard deviation was obtained using SPSS version 20. Wilcoxon Signed Ranks Test was used to find if any significant difference of the abilities of health professionals between the pre and post training score.

\section{RESULTS}

\subsection{Characteristics of respondents}

The Table 1 is based on the age of the respondents. The majority of respondents were aged over 30 years as many as $35(54.7 \%)$ people. Based on age, female respondents as many as $49(76.6 \%)$ people, while a minority of respondents were male as many as 15 (23.4\%) people. As many as $60.9 \%$ respondents reported length of work was more than 5 years.

Table 1. Characteristics of Respondents

\begin{tabular}{|c|c|c|}
\hline Characteristics & $\mathrm{n}$ & $\%$ \\
\hline \multicolumn{3}{|l|}{ Age (years) } \\
\hline $20-30$ & 29 & 45.3 \\
\hline $31-50$ & 35 & 54.7 \\
\hline \multicolumn{3}{|l|}{ Gender } \\
\hline Female & 49 & 76.6 \\
\hline Male & 15 & 23.4 \\
\hline \multicolumn{3}{|l|}{ Length of work } \\
\hline$<5$ years & 25 & 39.1 \\
\hline$>5$ years & 39 & 60.9 \\
\hline Total & 64 & 100 \\
\hline
\end{tabular}

\subsection{Bivariate analysis}

The study aimed to analyze the effect of primary liaison psychiatric services for HIV/AIDS patients on the abilities of health care workers to provide treatments. The instrument was scored by the researchers. The results of the pre and post training of primary liaison psychiatric services for HIV/AIDS patients on the abilities of health care workers to provide treatments scores are shown in Table 2. 
Table 2. Pretest and Posttest Scores of the Abilities of Health Care Workers

\begin{tabular}{lcc}
\hline The abilities of health care workers & $\mathrm{n}$ & Mean \pm SD \\
\hline Cognitive abilities & 64 & \\
Pretest & & $62.56 \pm 6.842$ \\
Posttest & & $76.25 \pm 4.730$ \\
Affective abilities & \\
Pretest & $63.86 \pm 4.173$ \\
Posttest & $78.64 \pm 4.591$ \\
Psychomotor abilities & \\
Pretest & $59.59 \pm 5.298$ \\
Posttest & $76.12 \pm 4.685$ \\
\hline
\end{tabular}

Wilcoxon Signed Ranks Test showed significant value of $<0.05(\mathrm{p}=0.000)$. It can be concluded that there is significance difference between pretest and posttest score after training of primary liaison psychiatric services for HIV/AIDS patients on the abilities of health care workers to provide treatments.

\section{DISCUSSION}

Primary care serves as the cornerstone to build connection between mental and physical health. The collaborative care can provide support to HIV patients with co-morbid physical and mental health problems in primary care, also effective for treatment of depression along with HIV disease [10]. About $60.5 \%$ HIV patients had depression, 21.5\% had psychosis and 7.1\% AIDS related dementia. Mental health issues in HIV patients have a major effect on the adherence to treatment and prognosis of the HIV [11].

Psychosocial intervention delivers to provide comprehensive treatment for HIV/AIDS patients. Psychosocial therapy can help HIV patients to accept their conditions, improve coping mechanisms and ability to cooperate with health care team [12]. Diagnosed with a chronic and stigmatizing disease also influence patients' psychological well-being. They need to have a positive coping strategies, adequate social supports and people to share their feelings [13]. In this study, health care workers were prepared as health agents to improve their abilities to provide treatments including mental health status.

Previous studies showed the effectiveness of developing liaison psychiatric services in primary care that there were $91.2 \%$ of physician stated positive effects for primary care management when giving support and 58.9\% noted positive effects for patient outcomes [14]. Liaison in primary care is a specific strategy to provide mental health care to HIV patients in the primary care setting. Liaison psychiatric activities also advanced the system in primary care which includes coordination, communication and integration of services. The role of the health care team is important for the integration of HIV care in the community through coordinated care incorporating all health domains [15]. Furthermore, there were consistent benefits of integration from the health care workers' perspective that it strengthen organizational system and their staff relationships, collaborative teamwork and motivational to manage the cases. Both physician and nurses work carefully to assess HIV patients and integrate the care service [16].

Consultation liaison in primary care is a health care delivery model in community which combined both physical and mental health care. This liaison services include providing health education, assisting in problem solving and other strategies to improve mental health status. Previous study showed that liaison care services enhance mental health status for about three months; and adherence to treatment for about 12 months in patients with mental health issues, mainly depressed patients [17].

Respondents stated that the training increased their knowledge about HIV treatment. They stated that the assessment was easier and simple to be used. Studies showed that simple screening tools have to be developed in order to help them to recognize mental health issues in HIV-infected patients. Additionally, it allowed respondents to build stronger relationships with HIV patients [18]. Respondents expressed difficulties to engage relationships with HIV patients as most of them felt guilty and afraid about social stigma if they described their conditions. However, health professionals knew that they have to improve their communication. Social stigma is instead a complex situation which can negatively impact the ability of people living HIV/AIDS. Therefore, it needs a public health policy to conquer the social stigma related to HIV/AIDS [19].

HIV patients experienced stigma such as feeling ashamed, blaming self because of being HIVpositive, feeling discriminated by societies, having loss of education or employment, feeling isolated from family members and friends. Liaison psychiatric services in primary care promote respect of human rights. Mental health intervention in primary care could minimize the stigma and discrimination [20]. It also provides good outcomes both for the patients and health care organization. Integrating mental health into primary care is based on evidence that mental health issues are over-represented in community. To facilitate 
better outcomes, primary care has been attempting to meet the needs of HIV patients regarding mental health treatment by providing health care services in sub rural areas. However, it needs further training program to increase the abilities of health care workers about mental health treatment.

Respondents showed improvements in psychomotor abilities to give psychosocial intervention in HIV patients. Several studies investigated the benefits of psychosocial therapies that it improved the wellbeing status as well as emotional distress among HIV/AIDS patients [21]. Psychosocial interventions include supporting the ability to cope with the illness, social stigma and interaction with their families and surroundings. Further, it has the potential to have a positive effect on mental health status and treatment adherence. Previous study showed that HIV patients have specific issues such as relationship problems, health disease control, drug/alcohol use and mood changes, emotional distress, social stigma, grieving and employment status [22].

\section{CONCLUSION}

HIV can be a source of major stress which can lead to changes in emotional problems such as depression, persistent sadness, feeling empty and anxiety. Common factors which can be found are social predisposition factors such as social stigma, homelessness, poverty and substance misuse. The ability of liaison officer in primary care could help patients reduce their psychiatric problems and at the same time can greatly affect patients' risks for transmission of HIV to others.

\section{ACKNOWLEDGEMENTS}

We would like to express our special thanks to all of the respondents for participating in this program. We also received support from Community-Integrated Health Center in East Java and School of Nursing, Faculty of Medicine, University of Brawijaya, to conduct this research.

\section{REFERENCES}

[1] UNAIDS, "HIV and AIDS Estimates," 2017.

[2] N. Jayarajan and P. S. Chandra, "HIV and Mental Health: An Overview of Research From India," Indian J Psychiatry, vol/issue: 52(1), pp. S269-S273, 2010.

[3] A. Schade, et al., "HIV-infected Mental Health Patients: Characteristics and Comparison with HIV-infected Patients from the General Population and Non-infected Mental Health Patients," BMC Psychiatry, vol. 13, pp. 35, 2013.

[4] S. Kaaya, et al., "Grand Challenges: Improving HIV Treatment Outcomes by Integrating Interventions for CoMorbid Mental Illness,” PLoS Med, vol/issue: 10(5), pp. e1001447, 2013.

[5] R. Subramoney, "The Lived Experience of Indian Women with HIV/AIDS in South Africa: A Phenomenological Inquiry," International Journal of Health Sciences, vol/issue: 3(2), pp. 61-121, 2015.

[6] Royal College of Psychiatrists, "The Management of Patients with Physical and Psychological Problems in Primary Care: A Practical Guide," College Report, 2009.

[7] P. Aitken, et al., "An Evidence Base for Liaison Psychiatry - Guidance," Strategic Clinical Network for Mental Health, Dementia and Neurological Conditions South West, 2014.

[8] N. Coupe, et al., "Facilitating Professional Liaison in Collaborative Care for Depression in UK Primary Care; A Qualitative Study Utilising Normalisation Process Theory," BMC Family Practice, vol. 15, pp. 78, 2014.

[9] A. J. Mitchell, "Is Liaison Psychiatry Effective in Primary Care?," BJPsych Advances, vol. 22, pp. 75-77, 2016.

[10] C. Naylor, et al., "Bringing Together Physical and Mental Health: A New Frontier for Integrated Care," London: The King's Fund, 2016.

[11] S. Roy, et al., "Patterns of Psychiatric Co-Morbidities In Patients of HIV/AIDS on Anti Retroviral Treatment," IOSR Journal of Dental and Medical Sciences (IOSR-JDMS), vol/issue: 16(4), pp. 57-61, 2017.

[12] J. S. McDaniel, et al., "Practice Guideline For The Treatment of Patients With HIV/AIDS," American Psychiatric Association, 2010.

[13] V. D. Heijden, et al., "Psychosocial group interventions to improve psychological well-being in adults living with HIV," Cochrane Database of Systematic Reviews, issue 3, 2017.

[14] N. Younes, et al., "Long Term GP Opinions and Involvement After a Consultation-liaison Intervention for Mental Health Problems," BMC Family Practice, vol. 9, pp. 41, 2008.

[15] L. Wilkes, et al., "The Role of the General Practice Liaison Nurse as Integrated Care Coordinator: A Delphi study," Clinical Nursing Studies, vol/issue: 4(3), 2016.

[16] S. M. Topp, et al., "Integrating HIV Treatment with Primary Care Outpatient Services: Opportunities and Challenges From A Scaled-Up Model in Zambia," Health Policy and Planning, vol. 28, pp. 347-357, 2013.

[17] D. Gillies, et al., "Consultation liaison in primary care for people withmental disorders (Review)," Cochrane Database of Systematic Reviews, issue 9, 2015. 
[18] M. Duffy, et al., "Integrating Mental Health and HIV Services in Zimbabwean Communities: A Nurse and Community-led Approach to Reach the Most Vulnerable," Journal Of The Association Of Nurses In Aids Care, vol/issue: 28(2), pp. 186-198, 2017.

[19] R. A. Burgess, "Supporting Mental Health in South African HIV-Affected Communities: Primary Health Care Professionals' Understandings and Responses," Health Policy and Planning, vol. 30, pp. 917-927, 2015.

[20] P. Bower, "Collaborative Models Between Primary Care and Specialist Services in The Management of Common Mental Health Problems," Clinical Neuropsychiatry, vol/issue: 8(4), pp. 243-251, 2011.

[21] J. P. Hernandez and M. J. Macgowan, "Psychosocial Intervention for Women with HIV/AIDS: A Critical Review," Research on Social Work Practice, vol/issue: 25(1), pp. 103-116, 2015.

[22] A. Amzel, et al., "Promoting a Combination Approach to Paediatric HIV Psychosocial Support," AIDS, vol/issue: 27(2), pp. S147-S157, 2013.

\section{BIOGRAPHIES OF AUTHORS}

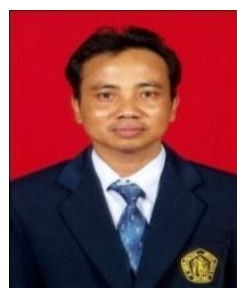

Ahsan is a lecturer in School of Nursing, Faculty of Medicine, University of Brawijaya. His specialty is in nursing management. He received his bachelor of nursing in Nursing Faculty, University of Pajajaran. His master of health science was achieved from University of Airlangga. His doctoral program achieved from University of Airlangga. Currently, he is a head of School of Nursing, Faculty of Medicine, University of Brawijaya.

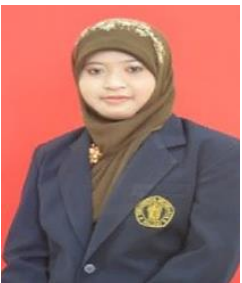

Retno Lestari is a lecturer in School of Nursing, Faculty of Medicine, University of Brawijaya. Her specialty is in mental health nursing. She received her bachelor of nursing in Nursing Faculty, University of Indonesia. Her master of nursing was achieved from Monash University, Australia. She also provides mental health counselling in community integrated village in East Java. 